This item was submitted to Loughborough's Research Repository by the author.

Items in Figshare are protected by copyright, with all rights reserved, unless otherwise indicated.

\title{
Design and evaluation: end users, user datasets and personas
}

PLEASE CITE THE PUBLISHED VERSION

http://dx.doi.org/10.1016/j.apergo.2013.03.008

\section{PUBLISHER}

(c) Elsevier Ltd and The Ergonomics Society

\section{VERSION}

AM (Accepted Manuscript)

\section{LICENCE}

CC BY-NC-ND 4.0

\section{REPOSITORY RECORD}

Marshall, Russell, Sharon Cook, Val Mitchell, Steve Summerskill, Victoria Haines, Martin Maguire, Ruth Sims, Diane E. Gyi, and Keith Case. 2019. "Design and Evaluation: End Users, User Datasets and Personas". figshare. https://hdl.handle.net/2134/12267. 
This item was submitted to Loughborough's Institutional Repository (https://dspace.lboro.ac.uk/) by the author and is made available under the following Creative Commons Licence conditions.

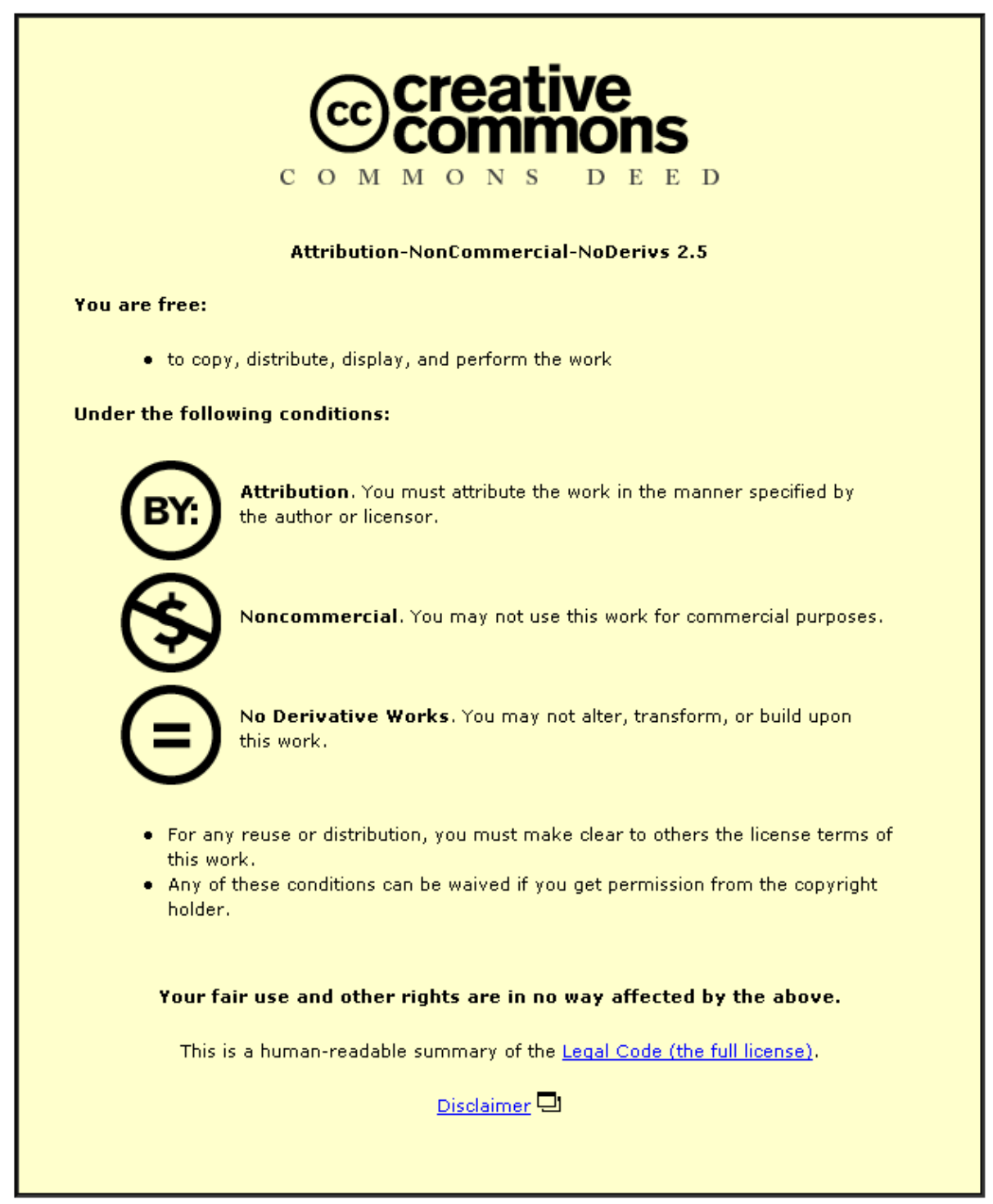

For the full text of this licence, please go to: http://creativecommons.org/licenses/by-nc-nd/2.5/ 


\title{
Design and Evaluation: End Users, User Datasets and Personas
}

\author{
Russell Marshall ${ }^{\mathrm{a}}$, Sharon Cook ${ }^{\mathrm{a}}$, Val Mitchell ${ }^{\mathrm{a}}$, Steve Summerskill ${ }^{\mathrm{a}}$, Victoria Haines ${ }^{\mathrm{a}}$, Martin Maguire ${ }^{\mathrm{a}}$, \\ Ruth Sims ${ }^{\mathrm{a}}$, Diane Gyi ${ }^{\mathrm{a}}$ and Keith Case ${ }^{\mathrm{b}}$, \\ ${ }^{\mathrm{a}}$ Loughborough Design School \\ R.Marshall@ lboro.ac.uk - Corresponding author (Tel: 01059222669 Fax: 01509 233999) \\ $\underline{\text { S.E.Cook@lboro.ac.uk }}$ \\ V.A.Mitchell@lboro.ac.uk \\ S.J.Summerskill2@lboro.ac.uk \\ V.J.Haines@lboro.ac.uk \\ M.C.Maguire@lboro.ac.uk \\ R.E.Sims@lboro.ac.uk \\ D.E.Gyi@lboro.ac.uk \\ ${ }^{\mathrm{b}}$ Department of Mechanical and Manufacturing Engineering \\ K.Case@lboro.ac.uk
}

\author{
All: \\ Loughborough University \\ Loughborough \\ Leicestershire \\ LE11 3TU
}

\begin{abstract}
Understanding the needs and aspirations of a suitable range of users during the product design process is an extremely difficult task. Methods such as ethnographic studies can be used to gain a better understanding of users needs, but they are inherently time consuming and expensive. The time pressures that are evident in the work performed by design consultancies often make these techniques impractical. This paper contains a discussion about the use of 'personas', a method used by designers to overcome these issues. Personas are descriptive models of archetypal users derived from user research. The discussion focuses on two case studies, the first of which examines the use of personas in the car design process. The second examines the use of personas in the field of 'inclusive design', as demonstrated by the HADRIAN system. These case studies exemplify the benefits 'data rich' personas contribute as opposed to 'assumption based' personas.
\end{abstract}

Keywords: personas, inclusive design, user-datasets

\section{Introduction}

Inclusive Design like other user centred design disciplines requires a focus upon user needs and requirements. However it is not always appropriate or possible to directly involve users in commercial design processes due to time, cost and logistical constraints. In light of this, approximations to end user requirements may have to be derived by other means. This paper explores the contribution of personas and existing user datasets, in this context. In addition, this paper explores a new approach through a software tool called HADRIAN that utilises the benefits of both developments. All of these design methodologies have developed in specialised fields; yet, taken together, they have the potential to provide both a psychological and physical underpinning to inclusive design applications in the future.

\section{Personas}

Personas are descriptive models of archetypal users derived from user research. They are a synthesis of multiple people who share similar goals, motivations and behaviours. Typically, between 1 and 7 personas will be developed to support a project with differences between each persona based on differences in goals and behaviours rather than demographics or market segments (Saffer, 2007). To encourage realism, and so increase engagement within the design team with these end user representations, each persona is given a realistic name, a photo, and a small amount of demographic information to make it seem like a credible representative of the user population. Pruitt and Adlin (2006) make the distinction between data driven and 
assumption driven personas. Data driven personas are grounded in user research and as such their validity can be high. However when there is little time to collect and analyse data, assumption based personas are often used to ensure that there is a shared understanding throughout the design team relating to who the users might be and their likely goals and motivations. Whilst the term 'persona' was first coined by Alan Cooper in the context of Interaction Design (Cooper 1999), personas within the Inclusive Design process for any product or service can be a powerful tool for understanding and visualising user goals, motivations, relationships with existing products and contexts of use.

\subsection{The Role of Personas}

The value of using personas to communicate user data to designers is recognised within Inclusive Design (Carmichael et al. 2005; Goodman et al. 2006). Carmichael et al. (2005) used theatre techniques encapsulated within video to communicate older users' experiences with technology to designers. They concluded this methodology increased the impact of personas as a tool for communicating user data to designers. Goodman-Deane et al. (2010) studied design practice to ascertain which user data formats are most acceptable to designers. They confirm that designers value design information that is quick and easy to use, visually stimulating, flexible, open ended and clearly and concretely related to design issues. Personas, the authors conclude, suit informal and flexible working and when visually compelling are ideally suited to engaging designers and fostering empathy with user needs. However, Goodman et al. warn that personas are not well suited to presenting detailed technical information about, for example disabilities, and their focus on archetypal users can make it hard to communicate the range of abilities within a population. As a project moves from the requirements and concept generation stages to the product development stage more specific data about the capabilities of users may be needed to supplement the use of personas.

Lähteenmäki and Kaikkonen (2004) describe other issues, such as how older users are often treated within design as a homogenous group whilst in reality they are as heterogeneous as any other customer segment, perhaps more so as age can bring a differentiation in needs because of variation in physical capability and life experiences. They also argue that within the body of research related to designing products for older adults, consideration of the motivational needs of users is under represented with the majority of research focussing on understanding how ageing has a detrimental effect upon the physical and cognitive abilities of users.

Sets of personas can be used within design to address some of these issues. Firstly, personas can be used to highlight the diversity in lifestyles present within an older population as shown in the case study below. Secondly, since personas emphasise the needs and motivations of users, they can be a powerful way of ensuring that inclusive design doesn't become overly focussed on overcoming barriers to product use but instead focuses upon the creation of positive user experiences for all. However the use of personas within design does not automatically lead to usable, useful and satisfying products since personas are only as good as the data they are built on (Nardi 1995). Pantzar (2002) warns that in the absence of actual user research (data driven personas) there is a tendency for self deception to creep into design. Well crafted and engaging assumption driven personas can provide a persuasive and compelling vision of users which masks a scarcity of real knowledge on user needs. Assumption based personas often reflect "marketing clichés" rather than the more everyday needs and characteristics of the actual target user population.

\subsection{Persona Development Case Study}

At its inception, the persona process was born from a need to embed end user needs within the software applications of digital products (Cooper, 1999), to add detail of user requirements within the design process. However the underlying principles make their application suitable to just about any field of design and, recognising this, the Design Team at the Ergonomics and Safety Research Institute (ESRI - *now Loughborough Design School) within Loughborough University transferred the methodology to the automotive sector as a mechanism for disseminating field research to Nissan's designers.

Primary research into the current and anticipated future lifestyle activities of Baby Boomer (born during the post-WWII baby boom) drivers was commissioned by Nissan. The methodological challenge was to anticipate how lifestyles and in particular factors relating to car use were likely to change as the current generation of baby boomers age. As each generation of adults has accumulated different cultural and product use experiences it is problematic to predict the needs and motivations of future older users from the 
behaviour of today's older generation. The ESRI Design Team used a variety of methods within the research:

- A Cultural Prime (Sleeswijk-Visser et al. 2005) was designed to sensitise the study participants to the focus of the research before attending the focus group sessions. Primes are a variation of the Cultural Probes technique (Gaver et al. 1999). They are used to provoke people to look closely at their current experiences and to begin to think about their aspirations and values. They also serve as a probe for the researchers by providing insight into the lifestyles of the study population. The prime consisted of a camera and a booklet containing a series of tasks and questions presented in an engaging and playful form. These addressed the participant's relationship to their current car, past vehicles they had owned, car journeys and cars of the future. The prime also began to move the participants towards considering how their car related needs might change with age - a topic that needed to be approached with sensitivity as the ability to drive is tied closely for many with the concept of independence.

- A series of Focus Groups were held in which participants' attitudes concerning current and anticipated future lifestyles were explored. (The Focus Groups comprised a total of 28 participants, equally split between the genders, whose mean age was 61 years (range was 55 to 67 years). Focus groups were also held with participants who were ten years older who were asked to reflect back on how their lives had changed over the previous ten years (mean age 69 years, range 65 to 75 years). The investigative methods used were:

- A 'Location Mapping' tool was designed to prompt participants to recount their typical use of the car. Based on the mobility mapping tool of Mitchell et al. (2004) this prompted recollection technique was used to elicit from each participant a range of typical journeys, detailing the purpose; frequency (daily, weekly, monthly, occasionally); distance travelled (local, regional, national, international) and their driver or passenger status

- Change analysis explored how participants' felt their lives might change over the next ten years in the key areas of family, friends, work, health, hobbies/leisure, holidays, shopping and finance. The participants then had to indicate the impact they considered these changes might have on future vehicle use (increase '+', about the same '0' or less '-'; See Figure 1 which illustrates the layout of the data collection sheet).

This first-hand data collection approach allowed data driven personas to be created. The collected data was summarised and then used as 'factoids' (key data points) within the persona development process as described by Pruitt \& Adlin (2006). Initial categories of user were identified in terms of user goals. Facts relating to these goals were then extracted from the focus group comments and other collected material, which formed the 'factoids'. These were then sorted to identify sub-categories and skeletons created and prioritised against the initial brief. Finally the highest priority skeletons were developed into full personas. Data were sorted and categorised independently by three researchers then reviewed collectively to reach consensus, to reduce individual partiality as much as possible. Additionally, through use of careful sampling (recruiting a wide variety of participants) and a mixed methods approach, bias was minimised. By following this process, five distinct personas were created reflecting the lifestyles of Baby Boomer drivers. These were:

- 'The Carer' persona who has responsibilities for transporting parents/partner either on pleasure trips or more regular visits, e.g. to hospital.

- The 'It's My Time' persona who is looking forward to spending their leisure time with increased travel and hobbies.

- 'The Enthusiast' persona who enjoys the experience of driving.

- 'The Thrifty Driver' persona who realises that, in retirement, they need to be more careful with their spending.

- 'The Reluctant Driver' persona who may not particularly enjoy driving and could feel pessimistic about driving in the future.

Each of the personas was presented for use by Nissan in a format exemplified by Figure 2 .

It is not possible to reflect here on the value of the created personas in this example since, having been created by ESRI, their application was undertaken in-house by Nissan. However work undertaken by the Ford Motor Company in this area provides some insight into their potential significance (Patton, 2009). 
This case study exemplifies the thorough use of a broad range of end user data gathering techniques to provide a major automotive manufacturer with a comprehensive set of data driven personas. The process used to generate these personas avoids the pitfalls of assumption based personas. Whilst their ultimate benefit is not thoroughly explored here it is clear that they are perceived as a useful tool within design and that the automotive industry sees them as a key part of their design strategy.

\section{Personas and User datasets: Complementary methodologies}

It is natural to believe that talking to real people is always the 'gold standard' when designers wish to understand their users and yet it is not a trivial exercise in terms of the resources required to undertake this in a valid manner. The challenges in employing end users within the design process can be considerable and include: knowing precisely the characteristics of the end users to target, accessing such end users in often global markets where they may be elusive or hidden from the designer, defining the information to be obtained and ensuring its validity, and the time commitment required for the process. Many of these issues are discussed in the literature relating to running user / fitting trials or focus groups (Porter \& Porter 2001; Greenbaum 1998). Where designers are unable to engage directly with the end users within the design process, then approximations can be made through the application of information about end users in the form of personas and / or user datasets. Whilst such data sources may suffer knowledge gaps compared to the ongoing involvement of end users, they have the compelling advantage of being readily accessible over extended time frames in a pre-processed form at low financial cost. Personas provide concrete, stable and focused information to designers (Pruitt \& Adlin, 2006) smoothing out the more transient aspects of human behaviour and motivations. As such they are of some appeal to designers who require information which provides more in-depth insight into users, yet is quick and cheap to use in informal and exploratory ways (Goodman-Deane et al, 2010).

Although both personas and user data sets both stand in place of real users within the design process, the roles performed by these two methodologies are complementary. Personas are focussed on goals, motivations and behaviours and may be viewed as being concerned with the psychological fit of the user to the product whereas datasets tend to focus on anthropometric data and may be viewed as being concerned with the physical fit of the user to the product. Ensuring that the product's development addresses both of these aspects may therefore help to improve its acceptance within the market place.

\section{User Datasets}

There are many existing sources of data on people that support design application. Datasets such as Adultdata (Peebles and Norris 1998), BodySpace (Pheasant 2003), Human Scale (Diffrient et al. 1974) and People Size (Open Ergonomics 2008) present body size, strength and performance data for the adult population for nationalities from around the world, whilst others such as Older Adultdata (Smith et al. 2000) focuses specifically on adults aged 50 years and over. However such data, which is essentially statistical tables, lacks personalisation and embodiment. In addition, much of this data does not fully support design application. Issues to do with percentiles, lack of correlation between body segments, and the relevance of measures taken in highly standardized postures, make application a complex and often misunderstood process (Porter et al. 2001).

A prime example of this is the issue of multivariate accommodation. Anthropometric (body size variability) data typically separates individual measures (arm length, sitting height etc) into separate tables, removing the link between these variables as exhibited by any one individual. This means that it is not possible to use the data sets to understand the variability in body size (such as the ratio of leg length to body length). This has particular impact when designing products that have a number of variables that require adjustment (multivariate), such as a car seating position. In the process of establishing an acceptable 'fit' for the population compromises in, for example, the posture adopted by a person, are likely to be made. These compromises become significant when the design in question has to meet the needs of the whole population including those who are older or who have disabilities. Typically, those who are older or who have some form of impairment are less able to adapt in this manner and thus these users are not merely disadvantaged, they are excluded. It is only by collecting new datasets that maintain the links between the anthropometric data for any one person, that these issues can be better understood. 
Addressing these issues of applicability and the development of a means to contextualise data concerning users became the focus of the HADRIAN project (Human Anthropometric Data Requirements Investigation and ANalysis).

\section{HADRIAN}

The Design Ergonomics Group at Loughborough University recognised the need to improve the data available to designers, ergonomists and engineers on older and disabled people together with a means to employ these data for design evaluations. Research funded by the EPSRCs Extending Quality Life programme (EQUAL) and later the Sustainable Urban Environment programme (SUE) resulted in HADRIAN (Marshall et al. 2009).

Driven by 50 user interviews (Gyi et al. 2000) and a pilot trial (Marshall et al. 2002), the HADRIAN database (Marshall et al. 2009) consists of physical and behavioural data on 100 individuals, aged 18 to 89 years. Body size and shape is captured through a comprehensive list of anthropometric measures spanning from 1st to 99th \%ile with at least one person in each decile. In addition the database provides joint range of motion data and covers over 20 recognised impairments including: cerebral palsy, epilepsy, multiple sclerosis, limb loss, arthritis and Parkinson's disease, with many individuals having more than one impairment. The data collected also span the full range of four of the most design relevant disability scales (Locomotion, Reaching and Stretching, Dexterity, and Personal Care) indicated in the Office of Population Census and Surveys (OPCS) severity scores (Martin et al. 1994). The full scope of the technical data associated with each individual includes: anthropometric body measurements, joint angle ranges of motion, reach range in the form of a reach envelope or volume, grip strength, manual dexterity and a range of more general information on age, occupation, nationality, work history, a range of activities of daily living and transport use. This data is also accompanied by two photographs taken from the front and side of the individual along with video data.

The data contained within HADRIAN is conveyed to designers by means of numerical data outputs, personal information, through videos of tasks being performed and through video clips of 'talking heads' of participants describing their experiences. The individuals in the HADRIAN database are initially presented much like personas. They have a name and a picture together with some background information. By extending the data in this way and personalising it, it was the intention of the HADRIAN team to engender a greater degree of empathy and understanding within designers and other practitioners (See Figure 3). One particular issue that HADRIAN intended to address by this methodology was that of anthropometric percentiles and their use for establishing design limits. Designing for $5^{\text {th }}$ to $95^{\text {th }}$ percentile has become a defacto standard and yet designing purely using these numbers conveys none of the actual impact of designing out the bottom or top 5\% of the population for any single measure. By personalising these data it was hoped that establishing design limits became a process of understanding individual needs and striving to accommodate as many people as possible rather than just making an arbitrary decision based upon a percentile. The data therefore provided within HADRIAN were selected to provide as broad a range as possible for every measure recorded in order to demonstrate to designers the need to challenge their designs to extend beyond the conventional design population.

In addition to providing data on people, HADRIAN also supports the use of the data for task analysis. Directly from the HADRIAN data, digital human models can be created within the SAMMIE system (Porter et al. 2004) and then used to perform a virtual fitting trial. HADRIAN provides the ability to define the task, and when combined with a CAD model of the design to be evaluated, the system can create virtual people with the same size, shape and abilities of the real people they mimic and get them to perform the task as described (see Figure 4). A key feature of this simulation is the behaviour of the virtual subjects. In attempting to perform the given task the system employs codified behaviour in the form of postures adopted when the real subjects were asked to perform tasks during data collection. These postures are then used to drive the postures adopted in the virtual environment. The analysis results in a percentage excluded giving a representation of the number of people who would be unable to perform the task with the given design. In addition to highlighting who failed the task, the system also indicates why failure occurred and allows the designer to adjust their design, or to try alternative concepts with the same task, thus examining the inclusiveness of any given design. 


\subsection{HADRIAN Validation Case study}

HADRIAN is currently being validated through two phases of validation case studies. The second of these studies is intended to explore HADRIAN's capability to evaluate stages of a journey. Using the Docklands Light Railway (DLR) station at Greenwich in London as a test bed, HADRIAN was used to evaluate the accessibility of making a journey through the station. The journey consisted of purchasing a ticket from the ticket machine at the station, navigating to the appropriate platform, and finally getting on the appropriate train. The journey was conducted virtually by the members of the HADRIAN database and assessed in the task analysis system and also by a carefully selected set of nine real people with a variety of impairments. The sample included: a male powered wheelchair user with cerebral palsy (56 years), a female powered wheelchair user with familial spastic paraparesis (36 years), a female manual wheelchair user with spina bifida (50 years), two ambulant disabled females who both use a walking stick (55 and 37 years), an ambulant disabled female who uses a wheeled frame ( 82 years) and three non disabled people. These included a UK male with 99th\%ile stature (36 years), and an Indonesian female with 1st\%ile stature (33 years). The third person without a disability was a 96 th\%ile stature UK female (32 years) who performed the task with a pushchair and two small children.

Comparing the nine real people with the virtual participants in the HADRIAN database shows that there is no one-to-one mapping of characteristics at the level of the individual. However, the range of characteristics displayed by the real people is represented within the HADRIAN database. For example, participant one in the Greenwich trial was 56 years old, exhibited limited upper limb dexterity and had limited mobility due to their cerebral palsy and use of a wheelchair. This person was not an individual in the HADRIAN database but as we have already seen, the database spans ages 18-89 with ten people in the 50-59 age range, and cerebral palsy is represented by one individual in the database. More broadly there are nine wheelchair users in the database and eighteen people who have limited dexterity such that turning a tap may pose them some difficulty. In addition, taking one other arbitrary datum as an example, the seated equivalent of stature for participant one was $1272 \mathrm{~mm}$ well within the range of $1097 \mathrm{~mm}$ to $1633 \mathrm{~mm}$ represented in the database.

The DLR station at Greenwich is a relatively modern station with ramps as well as stairs, lifts, level access, good seating and the like. However, it also has a significant underpass as the track is raised well above ground level. The participants all had to use the ticket machine, consisting of nine reach and vision task elements to interact with the various features (e.g. reach to coin slot, or view screen instructions). The participants had a choice of how to reach the platform, via stairs, lift or ramp and this would require between two and six reach and vision task elements depending on the route chosen. Finally there were four movement task elements to reach the platform that were all on level ground unless the participant chose to take the stairs or the ramp.

The preliminary results of the validation show that there were 10 task element failures for the real participants, all associated with the ticket machine. The most common failure (for three participants) was with the coin slot that is mounted high on the ticket machine. The second most common failure (for two participants) was with the note slot. The note slot is in a more accessible location when compared to the coin slot but requires a much more complex posture and high degree of dexterity to feed the notes into the machine. There were a number of other failures including for example the ticket and change retrieval tray which has a security flap that covers it during use which requires it to be pushed out of the way and then held out of the way whilst the tickets and change are collected.

The virtual assessment resulted in 68 task element failures 59 with the ticket machine and 9 with the lift controls. Again the most common failure was associated with the coin slot (for 27 virtual participants). Further similarities with the real participants included 19 virtual participants who failed to use the note slot, and 9 who failed to use the ticket tray. The control dial also proved to be problematic for 4 virtual participants though this had not been a problem identified in the real trial. Finally the platform select button in the lift proved to be problematic for 6 virtual participants due to the constrained environment, especially for mobility scooter users.

The results show that, in general, the accessibility of Greenwich DLR station is good with multiple options to reach the platform and a level access train. However, the accessibility of the station, and thus the ability for people to make a journey using this station is let down by poor design of the ticket machine that would 
ultimately prevent people from making a journey via this route unless they had a travel card or had purchased their ticket elsewhere.

The key aim of this validation was to investigate the predictive abilities of the virtual accessibility and inclusiveness evaluation offered by the HADRIAN system. A particular feature of that investigation was to understand the impact of the participants not being matched. This lack of matching was an attempt to evaluate if the 100 people in the HADRIAN database were suitably representative to identify the likely issues experienced by any subset of real people. Understanding the results of this evaluation would provide some insight into how HADRIAN would perform for its intended use, to support practitioners in design and planning activity and gain early feedback on accessibility before the need for prototypes and participants for user-trials.

The validation provides results that are not comparable on a like for like basis due to the deliberate lack of participant matching. None of the characteristics outlined earlier allow a definitive conclusion to be drawn that an individual is represented in the database. What the richness of data available does support is multiple levels of interrogation to provide confidence that the level of ability exhibited by an individual would be represented by the level of ability collectively demonstrated by the people within HADRIAN. In practice this further suggests that problems flagged by HADRIAN are likely to be those encountered by real people. From the validation results it can be shown that the same issues experienced by the real people were indeed demonstrated by at least one of the individuals in HADRIAN. In addition, the prevalence of the failures identified were in the same rank order for both real and virtual participants if not the same proportion of the samples. The virtual analysis also highlighted failures not encountered in the real trial. There is no way to establish if these failures would occur with real people but the data driven nature of the virtual analysis suggests that it would be prudent to investigate these issues further.

In addition to comparing task element failures by occurrence it is also import to address the nature of the failure. HADRIAN attempts to drive its analysis through observed behaviours and so the success or not of this process is embodied within the postures adopted in a resultant task element result. Whilst a thorough analysis of these real and synthesised postures is beyond the scope of this paper preliminary investigations suggest that HADRIAN can generate very realistic postures (see. Figure 4) however there are areas where the system fails to adequately replicate reality. Clearly more work is required to address some of the more fundamental postural discrepancies observed, in particular the orientation of wheelchair users to their interaction point where many wheelchair users take an oblique approach that was not properly represented in HADRIAN. In addition the system could not replicate some of the postural subtleties exhibited by real people. So for example, a participant using a particular feature of the environment as a support whilst bending down, or shuffling forward in their wheelchair seat to provide a greater reach range. Whether it is possible or indeed desirable to address some of these subtleties is a focus for future research.

Clearly this approach does not provide definitive answers to a practitioner wishing to understand the inclusiveness of their design and requires careful consideration to understand, evaluate, and then make some decision about the results. However, it also indicates that the HADRIAN database may be sufficiently representative to capture the majority of concerns that would need to be looked at to improve accessibility and inclusiveness. In this way the tool provides an evidence-based 'steer' to suggest where a design may be strong and where further investigation may be useful. All of this can also be performed at a point within a project where this form of feedback is particularly difficult to obtain in any other manner.

The evaluative abilities of the virtual analysis are driven by behaviour but are essentially physical in nature. In addition to the physical barriers, Greenwich also poses some psychological challenges due to the nature of the environment. Whilst the study with real people was conducted during the day and good lighting is present during the evening it is still not the most inviting environment. This perception was noted by the participants who did say that they may be put off making a journey via this station due to issues to do with their perception of personal security. HADRIAN also contains information about each person in the database regarding their thoughts about environments and their likelihood to avoid areas with a lot of graffiti or that are poorly lit. At present these data are not employed in any form of analysis. Thus it was not possible to assess if HADRIAN was capable of identifying the same issues raised by the real people automatically. At present the HADRIAN database takes a persona based approach to these cognitive and emotional issues, 
providing these data as characteristics of each of the participants or personas in the database to allow users of the system to gain an understating of the characteristics, motivations and needs of their potential users.

\section{Conclusion}

Personas and user datasets are complementary methodologies used to identify user requirements. Personas, which are concerned with understanding and visualising user goals, motivations, relationships with existing products and contexts of use, have a psychological focus and are used to define what users want to gain from using a product or service. They are also used as a communication tool to ensure that all those in, and associated with, the design team have the same understanding of the customer requirements for the product/service.

Conventional anthropometric datasets build upon this by helping to define how those requirements can be met. However, Loughborough University have developed a tool called HADRIAN which is unique in its scope, combining elements of both personas and user datasets. This combination of approaches is used within HADRIAN to allow the data to be presented in a variety of ways to suit the needs of the user. Data may be packaged to provide applicable technical data often associated with user datasets or to provide empathic attitudinal data often associated with personas. HADRIAN is of particular importance since it specifically relates to data on older and disabled people and assists its application to the design process thus encouraging and supporting good inclusive design practice. In this way, HADRIAN can be seen to accommodate the limitations of personas identified by Goodman-Deane et al. (2010) by combining the persona concept with the underlying technical detail needed to support the needs of design professionals.

It has been demonstrated through the case studies presented that where close, on-going contact with end users is not possible, personas can be used to approximate their requirements within the early phases of the design process whilst HADRIAN has shown that it is possible to provide an empathic, requirements driven approach with technical data to support inclusive design within the design development stage. Whilst the case studies given here concern two unrelated projects, it demonstrates the significant potential for both of these methodologies to be jointly applied within inclusive design in the future.

\section{References}

Carmichael, A., Newell, A. F., Dickinson, A., Morgan, M., 2005. Using theatre and film to represent user requirements. In: Proceeding of Include Conference Royal College of Art, London, 5-8 April.

Cooper, A., 1999. The Inmates Are Running the Asylum: why hi-tech products drive us crazy and how to restore the sanity, Macmillan Publishing Co., Inc. Indianapolis, IN, USA.

Diffrient, N; Tilley, A \& Bardagjy, J., 1974. Humanscale. Dreyfuss Associates. MIT Press.

Gaver, B., T. Dunne and E. Pacenti., 1999. "Cultural Probes." Interactions, January - February: 21 -29.

Goodman, J. and Clarkson, P.J. and Langdon, P.M., 2006. Providing information about older and disabled users to designers In: Human Computer Interaction (HCI), the Web and the Older Population, Workshop at HCI 2006, 12 Sept 2006, London, UK.

Goodman-Dean, J., Langdon, P.M. and Clarkson, P.J., 2010. Key influences on the user-centred design process. Journal of Engineering Design, 21, Issue 2\&3, April 2010, 345-373.

Greenbaum, T.L., 1998. The handbook for focus group research. Thousand Oaks, Calif.: SAGE

Gyi, D.E., Porter, J.M. and Case, K., 2000. Design practice and 'designing for all', Proceedings of the IEA

2000/HFES 2000 Congress, Human Factors and Ergonomics Society, San Diego, California, USA, August 2000, pp. 1-6.

Lähteenmäki, M. and Kaikkonen, A., 2004. Designing for Aged People Communication Needs, Workshop in British HCI 2004, 7th of September 2004, Leeds, UK.

Marshall, R., Gyi, D.E., Case, K., Porter, J.M., Sims, R.E., Summerskill, S.J. and Davis, P.M., 2009. A design ergonomics approach to accessibility and user needs in transport, Contemporary Ergonomics 2009, Bust, P.D. (ed), Taylor \& Francis, The Ergonomics Society Annual Conference 2009, London, UK, April 2009, pp. 51-60.

Marshall, R., Case, K., Oliver, R.E., Gyi, D.E. and Porter, J.M., 2002. A task based 'design for all' support tool", Robotics and Computer-Integrated Manufacturing, 18(3-4), 1st June 2002, 297-303.

Martin, J., Meltzer, H., Elliot, D., 1994. OPCS surveys of disability in Great Britain, Report 1: The prevalence of disability among adults. London: HMSO. 
Mitchell, V., Harker, S. and Eason, K., 2004. Mobility mapping - a discount technique for exploring user needs for future mobile products and services, Lecture Notes in Computer Science, Vol. 3160, pp. 476-480. Nardi, B., 1995. Some Reflections on Scenarios. Scenario-based Design: Envisioning Work and Technology in System Development. J. M. Carroll, John Wiley \& Sons, Inc. Open Ergonomics Ltd., (2008) People size 2008. Open Ergonomics Ltd.

Pantzar, M., 2002. "You Press the Button -We Do the Rest" - Writing Prospective History. Mobile Image. I. Koskinen, E. Kurvinen and T. Lehtonen. Helsinki, IT Press.

Open Ergonomics Ltd., 2008. People size 2008. Open Ergonomics Ltd.

Patton, Phil., 2009. Before creating the car, Ford designs the driver. The New York Times 16 July 2009.

Available on-line: http://www.nytimes.com/2009/07/19/automobiles/19design.html, Accessed: 4 December 2009.

Peebles, L. and Norris, B., 1998. Adultdata: The handbook of adult anthropometrics and strength measurements - Data for design safety. Department of Trade and Industry, UK. URN 02/798.

Pheasant, S., 2003. Body Space - Anthropometry, ergonomics and the design of work $-2^{\text {nd }}$ edition. Taylor $\&$ Francis.

Porter, J.M., Case, K., Marshall, R., Gyi, D.E. and Sims, R.E., 2004. 'Beyond Jack and Jill': designing for individuals using HADRIAN, International Journal of Industrial Ergonomics, 333, 1st March 2004, 249-264. Porter, J.M., Marshall, R., Freer, M. and Case, K., 2004. SAMMIE: a computer aided ergonomics design tool. In: N.J. Delleman, C.M. Haslegrave, and D.B. Chaffin eds. Working Postures and Movements - tools for evaluation and engineering. Boca Raton: CRC Press LLC, 454-462.

Porter, J.M. and Porter, C.S., 2001. Occupant Accommodation: An Ergonomics Approach", in An Introduction to Modern Vehicle Design, Happian-Smith, J, Butterworth-Heineman, 2001, 233-276.

Pruitt, J.S. \& Adlin, T., 2006. The persona lifecycle - Keeping people in mind throughout product design. Elsevier Inc.

Saffer, D., 2007. Designing for Interaction - Creating Smart Applications and Clever Devices AIGA Design Press.

Sleeswijk-Visser F., Stappers P.J., Lugt R. van der, Sanders E.B.N., 2005. Context mapping: experiences from practice. In Co-design, 1 (2), pp. 119-149.

Smith, S.; Norris, B. and Peebles, L., 2000. Older Adultdata: The handbook of measurements and capabilities of the older adult - Data for design safety. Department of Trade and Industry, UK. URN 00/500.

\section{Figure Legends}

What do you think will be the main changes in your life over the next 10 years (Write in the boxes below).

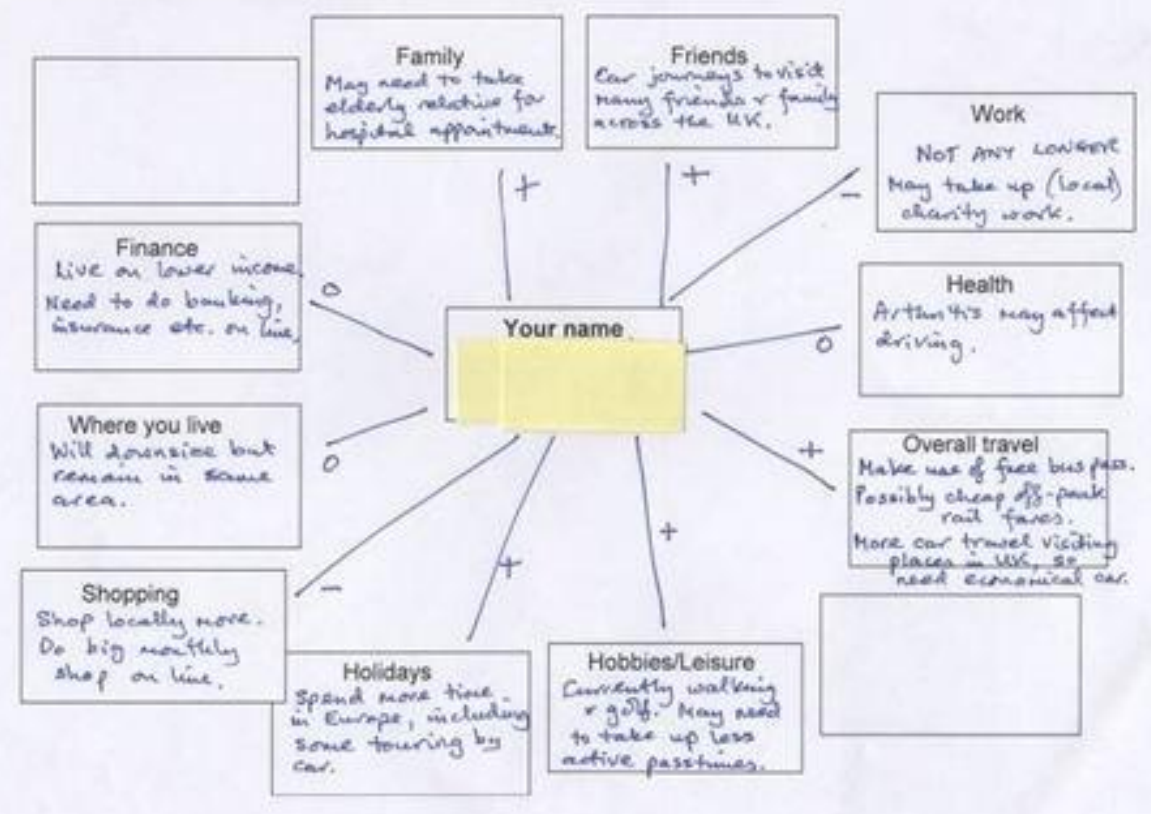


Figure 1: Focus group data collection sheet example: Change analysis

\section{It's My Time}

William is 61 and is semi-retired from his job as a architect. His two children have grown up and moved out of the family home. He is married to Patricia and they are both in good health.

Goals: William enjoys spending time doing the things he wants - tennis, walking, photography and holidays, which may involve driving to many places carrying equipment. $\mathrm{He}$ is looking forward to retiring completely and visiting China and New Zealand with his retirement lump sum.

Design challenges: William and his wife both enjoy caravanning. They need a vehicle with power and storage space to allow them to indulge in all their leisure pursuits.
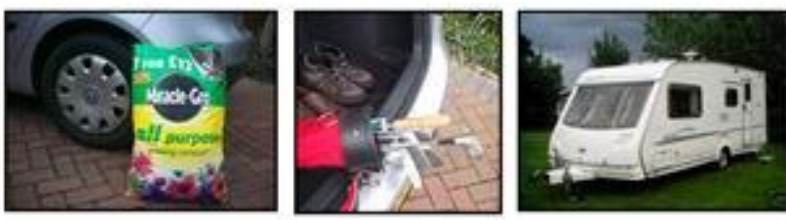

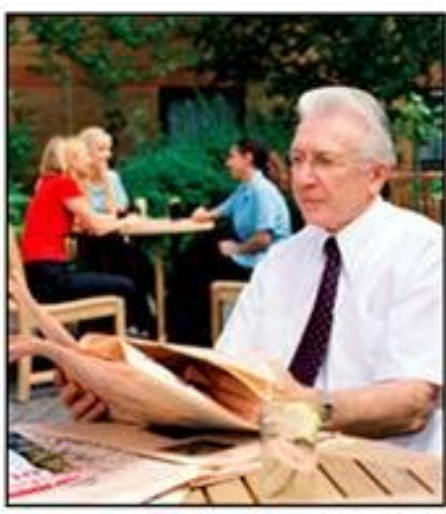

"My overall trave/ will increase as / will be able to spend more time on my hobbies".

"Going Places"

Figure 2: It's My Time persona

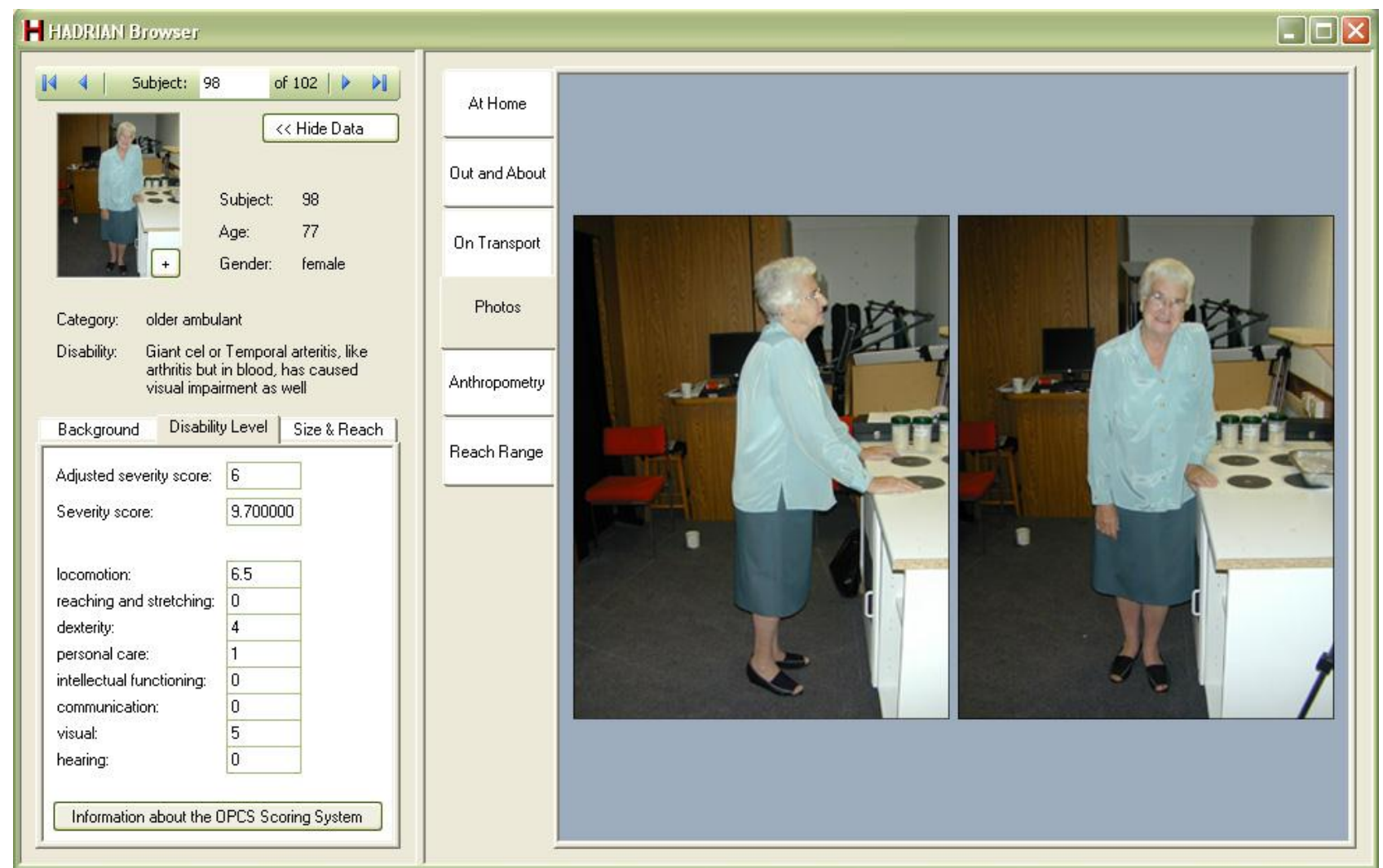

Figure 3: An individual presented in HADRIAN 


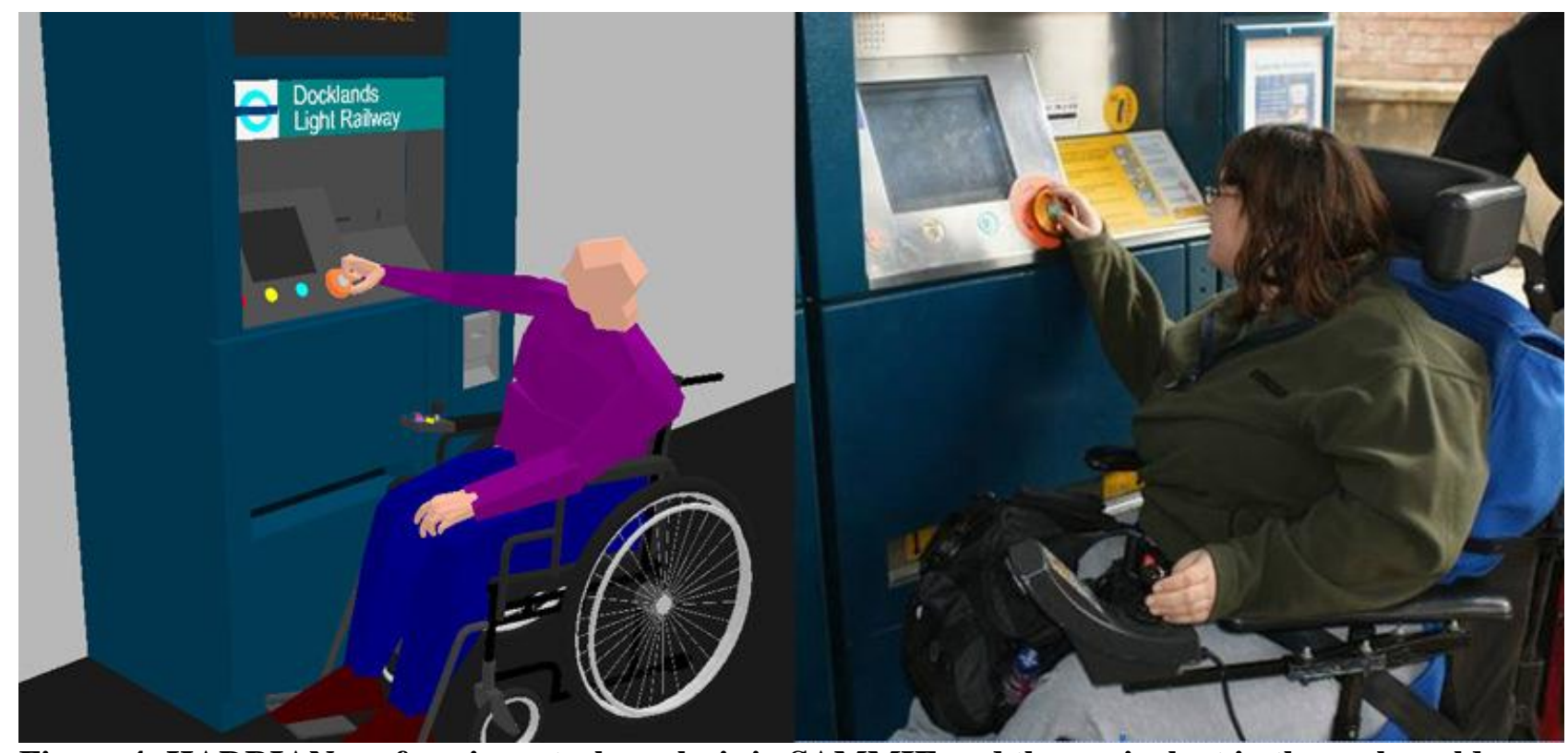

Figure 4: HADRIAN performing a task analysis in SAMMIE and the equivalent in the real world 